\title{
The Productivity of Soybeans Depending on the Conditions of Moisture Supply to the Soil
}

\author{
Shevnikov Mykola ${ }^{1}$, Milenko Olha ${ }^{1}$, Lotysh Ihor $^{2}$, Shevnikov Dmytro ${ }^{1}$, Shovkova Oksana ${ }^{3}$ \\ ${ }^{1}$ Faculty of Agrotechnology and Ecology, Department of Plant Breeding, Poltava State Agrarian Academy, Poltava, Ukraine \\ 2،Agrarian-economic Professional College Poltava State Agrarian University” Economic Department, Poltava State Agrarian Academy, \\ Poltava, Ukraine \\ 3“Agrarian-economic Professional College Poltava State Agrarian University” Technological Department, Poltava State Agrarian Academy, \\ Poltava, Ukraine
}

Email address:

shevnikov@ukr.net (S. Mykola)

\section{To cite this article:}

Shevnikov Mykola, Milenko Olha, Lotysh Ihor, Shevnikov Dmytro, Shovkova Oksana. The Productivity of Soybeans Depending on the Conditions of Moisture Supply to the Soil. American Journal of Agriculture and Forestry. Vol. 9, No. 4, 2021, pp. 211-218.

doi: 10.11648/j.ajaf.20210904.17

Received: June 22, 2021; Accepted: July 5, 2021; Published: July 13, 2021

\begin{abstract}
The connection of moisture content in the soil to the total productivity of plants has been established. Indicators of photosynthetic activity of soy crops were higher in years, with better moisture resistance. Fluctuations in the net productivity of photosynthesis over the years ranged from 5.3 (the driest year) to $7.0 \mathrm{~g} / \mathrm{m}^{2}$ day (a moisturizing year). The average indicator of the net productivity of photosynthesis during the years of favorable moisturizing was $6.5 \mathrm{~g} / \mathrm{m}^{2}$ day, in arid years it decreased by $10.8 \%$. The photosynthetic potential of soybean crops on average for 5 drought years was at the level of 2.5 million $\mathrm{m}^{2} /$ day during the period of branching - flowering, then it was reduced by $16 \%$, which was a direct effect of lack of moisture in the soil. During the years of favorable soil moisture, the photosynthetic potential was quite high and remained for a longer period within 2.7 million $\mathrm{m}^{2}$ / day. The total height of plants in dry years was lower and amounted to $74.5 \%$ of sufficiently wet years. On average, 18.1 beans were formed on one plant in arid conditions, this indicator was - 29.0 beans with favorable moisture, which was higher by $60.2 \%$ compared to previous indicators. Losses from the fall of generative organs during the growing season were significant in dry years - 81.9 , favorable for moisture $-78.0 \%$. In conditions of sufficient moisture, the number of beans with three seeds was increased.
\end{abstract}

Keywords: Soybean, Soil Moisture, Photosynthetic Activity, Productivity

\section{Introduction}

The productivity of agricultural crops in the Forest-Steppe of Ukraine depends mainly on the soil moisture conditions, and the components of the agricultural system (species and varietal selection of crops, tillage, fertilizer application system, etc.) are assessed primarily in terms of their impact on accumulation, conservation and economical use of moisture [1]. In order to identify the impact of certain environmental factors on soybean yield, it was found that the sum of effective temperatures in the Forest-Steppe is quite sufficient for growing early and medium-ripe soybean varieties. A more significant factor is the unstable and uneven soil moisture during the growing season [2].
Historical experience indicates that selection for drought resistance in order to increase soybean productivity is a difficult task, and the progress in this direction is very slow. Given the great variability of moisture conditions over time, in some years the drought resistance of the sort is crucial, in others - its potential productivity, resistance to lodging and disease [3].

Significant growth of the aboveground mass of most crops is observed with the maximum use of solar energy, sufficient supply of nutrients and normal moisture supply. Prolonged drought during the soybean growing season causes significant irreversible changes - the active leaf surface decreases, the leaves turn yellow and dry up. Reducing the area of the photosynthetic apparatus accordingly reduces the synthesis of organic matter [4]. 
The characteristics of the water regime are determined by the inflow of water into the soil and its use, i.e. water balance. If the formation of the vegetative mass of early spring crops mainly depends on the autumn-winter and spring moisture reserves in the soil, then for the formation of the soybean crop precipitation is important during the growing season [5]. Researchers point out the special importance of the nature of precipitation distribution during the growing season, the closer this distribution is to the needs in the critical period for plants, the more productively water will be used for crop formation [6-8].

The study of the nature of growth and development of soybean plants has established a close relationship with soil moisture reserves during the sowing period. This is of particular importance for obtaining a friendly germination. In the future, due to increasing plant requirements for environmental conditions, there is competition between plants, primarily for moisture. Among the external factors that can reduce the irrational consumption of water by plants include the use of fertilizers $[9,10]$.

The highest productivity for soybeans is characteristic in the years when during the formation of generative organs there is increased cloudiness and at least 200-250 $\mathrm{mm}$ of precipitation. The critical period of water consumption should not coincide with the greatest deficit of moisture in the soil. Legumes have a negative perception of both moisture deficiency and excessive moisture in the root zone. There is a lot of data in the literature on the sensitivity of root nodules, and at the same time the process of symbiotic nitrogen fixation to water deficiency $[11,12]$.

Lack of moisture in the soil can cause both irreversible and reversible damage to the symbiotic nitrogen-fixing system, which leads to damage to the structure of the nodules as a result of the mechanical effect of desiccation [13]. As a result of drought, the flow of photosynthesis products into the nodules may stop when the plants dry out. The progressive consumption of nitrogen-fixing activity in soybean nodules when their surface dries is associated with the decrease in the rate of oxygen diffusion into the middle of the nodules [14]. Lack of water primarily kills plants that grow on symbiotically bound nitrogen, compared to legumes, which receive mineral nitrogen in the form of fertilizers [15].

This list of problems in the practical implementation of soybean cultivation technology requires the study of the effects of drought, both on individual physiological processes and on the growth, development and productivity of soybean plants. To identify the stress factor, it is necessary to grow plants in strictly controlled conditions. But artificial modeling of stress regimes is significantly different from field conditions. This requires many years of field research with a large number of arid and favorable years, which helps to identify the appropriate impact of soil moisture on the main indicators of soybean productivity in comparison with changes in meteorological factors and dynamics of soil moisture.

\section{Method}

The aim of our researches was to study the productivity of soybeans depending on the soil moisture conditions of the left-bank part of the Forest-Steppe. For this purpose, we used data for 10 years, of which 5 years were favorable for moisture, when more than $200 \mathrm{~mm}$ of precipitation fell during the growing season $(2010,2011,2014,2016,2017)$ and 5 years - drought-resistant with precipitation less than $200 \mathrm{~mm}$ for the growing season $(2009,2012,2013,2015$, 2018). Characteristics of vegetation conditions for the two groups of years are given in table 1. The soil of the experimental area is chernozem podzolic medium-loam with a humus content of $3.7 \%, \mathrm{pH}$ (salt) -5.6 . The main biometric records were performed on the main phases of plant growth and development. The scheme of the field experiment involved the study and comparison of the impact on crop productivity indicators, elements of crop structure. The soybean sort Ustya was studied in the field experiment. The soybeans were sown with ordinary row sowing with row spacing of $15 \mathrm{~cm}$. The soybean sowing rate in the experiments was 700 thousand similar parts per 1 ha, soybean sowing period was determined by establishing a constant soil temperature at the depth of seed wrapping within $12^{\circ} \mathrm{C}$.

Table 1. Soil water balance and average daily air temperature depending on the influence of meteorological factors in the zone of unstable moisture.

\begin{tabular}{|c|c|c|c|c|c|c|c|c|c|c|}
\hline \multirow{2}{*}{ Indicators } & \multicolumn{10}{|l|}{ Years } \\
\hline & 2009 & 2010 & 2011 & 2012 & 2013 & 2014 & 2015 & 2016 & 2017 & 2018 \\
\hline \multicolumn{11}{|l|}{ Productive moisture in the soil layer, $\mathrm{mm}$} \\
\hline $0-30 \mathrm{~cm}$ & 42,3 & 44,5 & 40,2 & 43,4 & 42,2 & 49,1 & 50,2 & 46,3 & 48,2 & 50,2 \\
\hline $0-50 \mathrm{~cm}$ & 81,4 & 83,4 & 75,3 & 85,2 & 81,4 & 93,0 & 94,2 & 83,2 & 100,5 & 92,4 \\
\hline $0-100 \mathrm{~cm}$ & 168,2 & 170,5 & 152,1 & 161,2 & 158,4 & 186,3 & 318,5 & 207,8 & 229,5 & 235,4 \\
\hline The amount of precipitation per year, $\mathrm{mm}$ & 545,1 & 592,8 & 428,2 & 459,4 & 430,2 & 594,6 & 669,5 & 619,0 & 756,0 & 769,8 \\
\hline incl. during the growing season, $\mathrm{mm}$ & 172,0 & 244,2 & 263,8 & 156,8 & 122,0 & 260,2 & 197,2 & 206,2 & 328,0 & 200,0 \\
\hline $\begin{array}{l}\text { Productive moisture in a meter layer of soil } \\
\text { during harvesting, } \mathrm{mm}\end{array}$ & 97,9 & 84,5 & 104,7 & 94,8 & 82,4 & 98,5 & 89,2 & 84,3 & 108,4 & 95,2 \\
\hline $\begin{array}{l}\text { The average daily air temperature during the } \\
\text { growing season, }{ }^{\circ} \mathrm{C}\end{array}$ & 18,4 & 18,7 & 19,1 & 18,9 & 17,5 & 17,7 & 19,1 & 20,0 & 18,1 & 19,5 \\
\hline Seed yield, $\mathrm{t} / \mathrm{ha}$ & 2,07 & 1,84 & 0,98 & 0,88 & 0,87 & 0,65 & 1,75 & 1,24 & 2,01 & 2,12 \\
\hline
\end{tabular}

This temperature regime of the soil was observed in the calendar period from April 26 to May 10 in different years of the research. The estimated area of the site is $25 \mathrm{~m}^{2}$, the repetition of the experiment is four times. In parallel with this 
experiment, a model experiment was established. A modification of the method for studying the individual productivity of soybean plants is proposed. The scheme of the experiment involved sowing soybeans by the beam method proposed by J. A. Nedler (1962) and described by W. Duncan (1986) and D. B. Egli (1988) in the United States. Taking into account the specifics of new domestic intensive sorts of soy, increase the yield of seeds while narrowing the row spacing and increasing plant density per unit area. The model experiment was laid out in such a way that the nutrition area of one plant gradually increased with its distance from the center of the circle. To eliminate the detrimental effect of the first soybean plants on each other in adjacent rays emanating from the center of the circle, to create the same conditions for plants in terms of variants and to increase the level of reliability of the obtained research results.

Grain harvesting was carried out by small grain harvesters "Sampo". The bunker mass of seeds after sorting was converted to $14 \%$ moisture. The yield of green mass was taken into account manually by weighing the mass of plants on the site. Seed productivity was determined by analysis of sheaf samples taken at each site of the experiment from $1 \mathrm{~m}^{2}$. The beans were plucked and counted from the plants, threshed, and the seeds were counted and weighed. The average number of beans per plant, the number of seeds in one bean was determined. Before harvesting, the dynamics of seed maturation was observed.

Conclusions on the reliability of the obtained data were made on the basis of a sample using correlation, regression and analysis of variance. Microsoft Excel, Statistica program module were used.

\section{Results}

In order to determine the influence of certain environmental factors on the yield of soy, it was established that the amount of effective temperatures in the left-bank forest-steppe is quite sufficient for the cultivation of early ripening and mid-season sorts of soy. A more significant factor is the unstable and uneven soil moisture during the growing season. In this regard, it is required to study the impact of the water regime of the soil, namely the lack of water, on the productivity of soy. Water balance was determined by the difference between water uptake and use by plants. The water balance is influenced by environmental conditions, humidity, amount and distribution of precipitation, the height of groundwater, the direction and strength of the wind. Soil water reserves in the spring determine the conditions of growth and development of soybean plants in the germination-branching phase. In almost all years of the research, the content of productive moisture in the meter layer of soil in the spring period was favorable for seed germination. The reserves of productive moisture in the 30-centimeter layer of soil were in the range of 42.2-50.2 $\mathrm{mm}$. Such reserves of moisture ensured the receipt of friendly germination with sufficient heat.

The amount of precipitation per year varied in different years from $430.2 \mathrm{~mm}$ in 2013 to a maximum of $769.8 \mathrm{~mm}$ in 2018. For soybeans, precipitation in the middle of the summer period, which falls on the flowering period - the formation of beans, is important. Their distribution in different years of research was very uneven from $122.0 \mathrm{~mm}$ in 2013 to $328.0 \mathrm{~mm}$ in 2017.

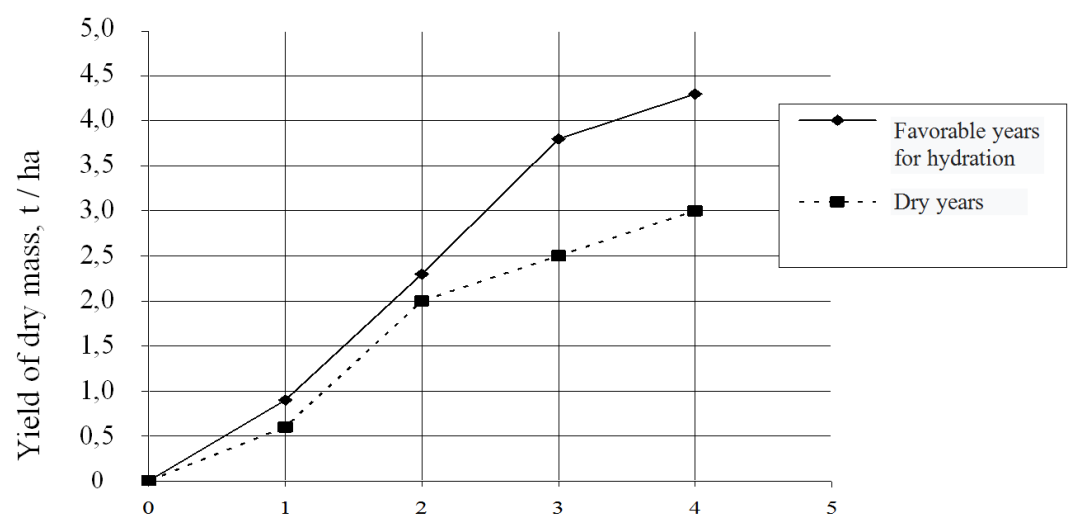

Figure 1. Accumulation of dry mass of soybean plants on average for 5 favorable years for moisture and 5 dry years for the phases of development of 1branching, 2-beginning of flowering; 3-formation of beans; 4-green ripe beans.

The duration of the sowing-seedling period differed slightly from year to year, ranging from 9-15 days. Elevated temperatures in dry years have reduced the length of the period from germination to branching. During the next vegetation of plants, there was a lag in the accumulation of dry mass of plants in dry years, which was determined by a reduction in the duration of all subsequent interphase periods, as well as a decrease in average daily weight gain (Figure 1). Reducing the duration of the growing season has two aftermaths a) decreases the height of plants and the height of attachment of the lower beans; b) the duration of the assimilation apparatus is reduced, which causes a decrease in plant productivity by $15-17 \%$, in some years to $20-25 \%$. The average daily gain of dry mass was determined as two values of the amount of aboveground mass synthesized over the appropriate period of time and the rate of its formation, which is characterized by the relative growth rate and determined by the ratio of average daily gain to average overground mass ( $\mathrm{g} / \mathrm{g}$ day). 


\section{Discussions}

The value of the average mass, which is defined as half of the initial (starting) and final mass for the respective period, is influenced by the conditions of the previous period. There was a lag in the growth of aboveground mass, which in the next growing season increased with increasing duration of the dry season, respectively, decreased the possible values of the average daily growth of biomass. It is also possible that the increased temperature regime of dry years caused the acceleration of biological processes, partially compensating for the negative effects of drought.

To determine the impact of growing conditions on the accumulation of plant biomass compared the most contrasting years of moisture 2017 - the most productive year for soybeans, moisture was normal throughout the growing season, precipitation during the growing season $328 \mathrm{~mm}$ (including July-August - $158.8 \mathrm{~mm}$ ); 2012 - arid with long periods without rain, precipitation during the growing season - $156.8 \mathrm{~mm}$ (including July - August - $36.9 \mathrm{~mm}$ ).

The data given for two periods of growing season from branching to flowering, and from the beginning of the formation of beans to their green ripeness indicates significant differences in the accumulation of above- ground mass (Table 2). The duration of the first period (branching-beginning of flowering) was accelerated under arid conditions by an average of two days, in the next accounting period this difference has become more significant. Under favorable conditions of moisture in the period of branching-flowering, the average daily gain of dry weight was high, the increase in dry weight of plants for the first period was $4.15 \mathrm{t} / \mathrm{ha}$, in arid it was $-3.78 \mathrm{t} /$ ha. The decrease in the average daily gain of dry weight was due to lower starting masses. Taking into that the vegetation of plants in arid conditions were accelerated, the value of the relative growth rate was higher than in the wet year.

An even greater differentiation of the growth of aboveground mass was by year during the flowering period of plants. There were the significant differences in the dry mass of plants at the beginning of the period. The magnitude of the increase in dry mass in favorable years for moisture was greater by $20 \%$ than in the arid years.

The tendency towards relative growth rates has persisted. The difference between the variants of the experiment was determined by the rate of leaf death and, perhaps the differences in the meaning of relative growth rate are associated with a different ratio of living and dead parts in plant biomass.

Table 2. Vegetation conditions and growth of dry aboveground mass of soybean plants in contrasting moisture years.

\begin{tabular}{lll}
\hline Indicators & Favorable moisture year & Dry year \\
\hline Branching - the beginning of flowering & & 17,5 \\
Average daily temperature & 18,1 & 17 \\
Duration of the period, days & & 1,75 \\
Dry weight of plants, $\mathrm{t}$ / ha & 1,87 & 3,78 \\
- at the beginning of the period (starting) & 4,15 & 5,53 \\
- increase for the period & 6,02 & 325 \\
- at the end of the period & 317 & 18,6 \\
The average daily increase in dry weight kg / ha & 17,0 & 22,7 \\
\% of starting weight & & 32 \\
Bean formation - green ripeness of beans & 18,9 & 3,95 \\
Average daily temperature & 36 & 2,78 \\
Duration of the period, days & & 6,73 \\
Dry weight of plants, $\mathrm{t}$ / ha & 4,38 & 210 \\
- at the beginning of the period (starting) & 4,02 & 5,3 \\
- increase for the period & 8,40 & 233 \\
- at the end of the period & 5,3 & \\
The average daily increase in dry weight kg / ha & & \\
\% of starting weight & & \\
\hline
\end{tabular}

This hypothesis was partially confirmed by the indicators of photosynthetic potential and pure performance of photosynthesis (Figure 2). The fact is that when measuring the leaves for subsequent calculations of these indicators took into account only the green leaves. Based on the fact that the pure productivity of photosynthesis is one of the important indicators that characterizes the photosynthetic activity of plants. It is known that the average indicator of the net productivity of photosynthesis determines the productivity of plants depending on the techniques of cultivation.

The indicators of photosynthetic activity of soybean crops were much higher in years with better moisture supply. This difference was especially significant in the critical period of soybean water consumption such as flowering, formation and formation of beans. Fluctuations in the rate of net productivity of photosynthesis by years ranged from 5.3 (the driest in 2013) to $7.0 \mathrm{~g} / \mathrm{m}^{2}$ day (favorable for moisture in 2017). In general, the average net productivity of photosynthesis for years of favorable moisture was $6.5 \mathrm{~g} / \mathrm{m}^{2}$ day, in dry years it decreased to 5.8 $\mathrm{g} / \mathrm{m}^{2}$ day. During the formation of beans, the net productivity of photosynthesis was slightly lower than in the previous accounting period. In dry years, the rate of net productivity of photosynthesis was determined primarily by the conditions of moisture in a given year or in some years it was higher (2009 - 6.2; $2013-5.95 \mathrm{~g} / \mathrm{m}^{2}$ day), in others 
years - slightly lower $(2010-5.7 ; 2012-5.7 ; 2015-5.25 \mathrm{~g}$ $/ \mathrm{m}^{2}$ day). On the average, over 5 years of the research, the net productivity of photosynthesis in arid conditions in the bean formation phase decreased by $2-3 \%$.

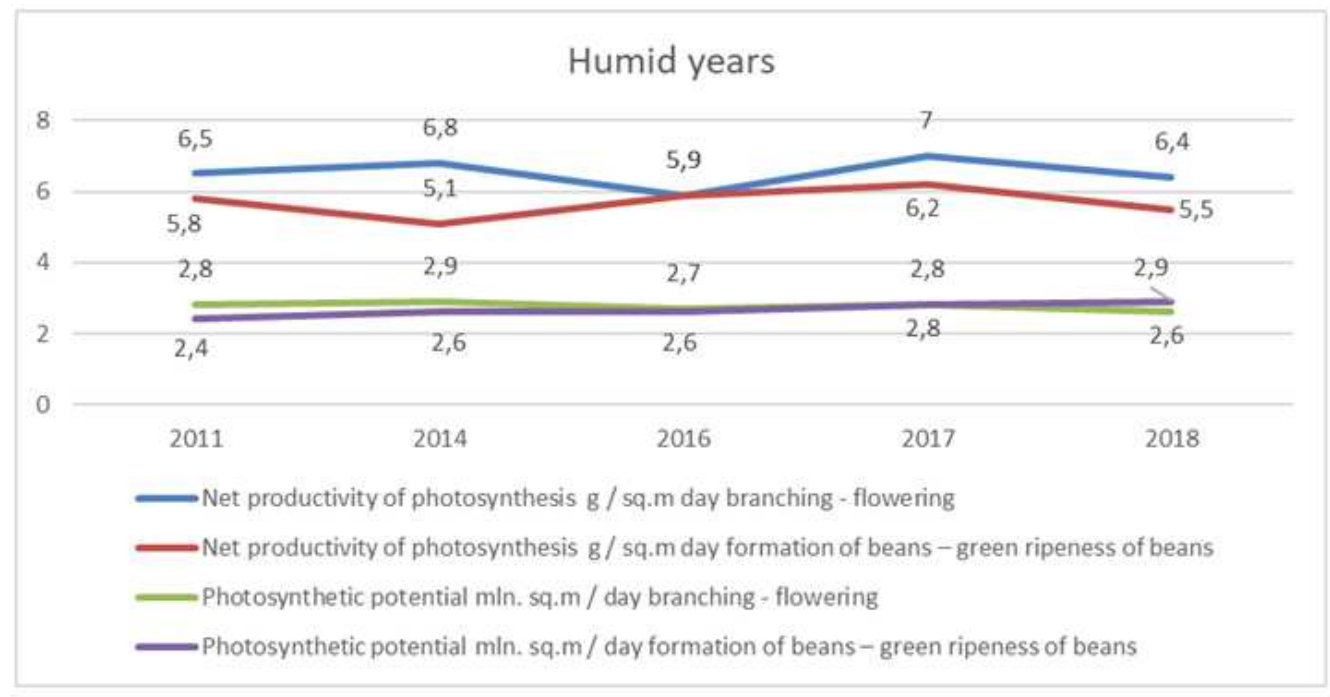

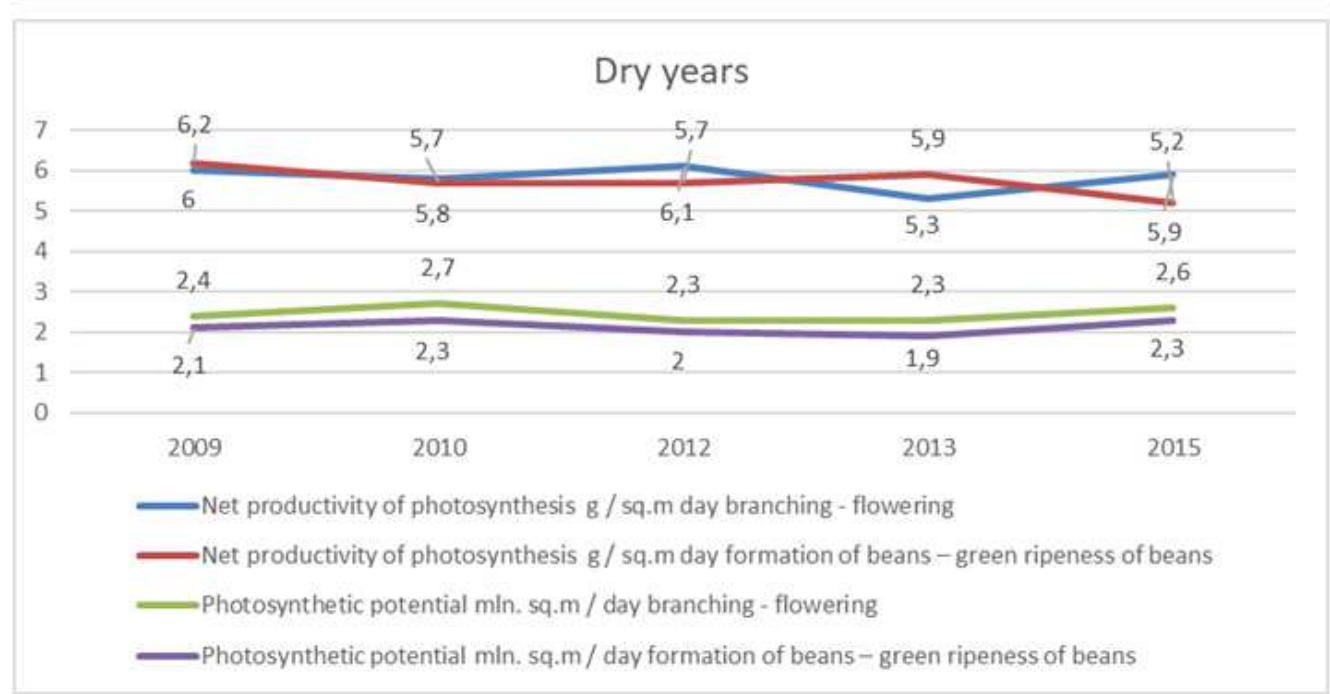

Figure 2. Net productivity of photosynthesis (NPF) and photosynthetic potential (PP) of soybean crops in different moisture content years.

The improvement of water consumption conditions had a positive effect on the increase of the photosynthetic potential of soybean sowing, which characterizes the periodicity of the changes in the leaf surface area and the total time of its active functioning. This indicator depends not only on the maximum indicators of the leaf surface, but also on the conditions of the formation and duration of active functioning of the leaves. The photosynthetic potential of soybean crops on the average for 5 dry years was at the level of 2.5 million $\mathrm{m}^{2} /$ day during the branching-flowering period, then it was reduced by $16 \%$, which was a direct effect of lack of moisture in the soil. During the years with favorable soil moisture, the photosynthetic potential was quite high and remained for a very long period within 2.7 million $\mathrm{m}^{2}$ / day. The overall activity of the leaf surface during the years with favorable water consumption was much higher and did not decrease for a long time. In years with the dry growing season, the photosynthetic activity of crops decreased in the phase of bean formation.
Thus, drought primarily affects the general factors of soybean productivity through growth and morphogenesis, reducing the size and the size of the leaf surface, the number and the size of branches, accelerating the aging and death of vegetative organs and plants in general. The activity of assimilation organs in conditions of insufficient moisture was not lower than in favorable years of moisture. The significant decrease in the photosynthetic apparatus was observed only in the case of deep and prolonged lack of moisture as its aftereffect increased, which is explained by the low availability of soil moisture for plants in the dry years.

Insufficient soil moisture has also affected the formation of the generative and reproductive spheres of plants throughout the growing season. It is necessary to highlight a number of main possible actions associated with the stages of organogenesis of generative organs. The greatest impact in the overall decrease in soybean productivity in the dry years is the decrease of appearing in the number of beans.

Soybeans are known to be a monsoon climate by origin, and 
a slight decrease in relative humidity has a significant effect on the formation of beans. In this case, there is a combined effect of water deficit and elevated temperature background. The latter, of course, is not extreme, but there is a reduction in the total duration of bean segmentation and laying the number of seeds (Figure 3). Arid conditions of the growing season have a negative effect on the elements of the structure of the soybean harvest. Given the origin and conditions of soybean formation as a crop, high productivity is characterized by sufficient soil and air moisture and sufficient heat. The total height of plants on average for 5 dry years was lower and was $74.5 \%$ of the average 5 sufficiently moisture-provided years. Other indicators of the structure of the soybean harvest were also lower than the number of beans per plant - by $17.6 \%$; the number of seeds per plant - by 15.1; weight of 1000 seeds - by 14.3 ; weight of seeds from one plant by $31.5 \%$.

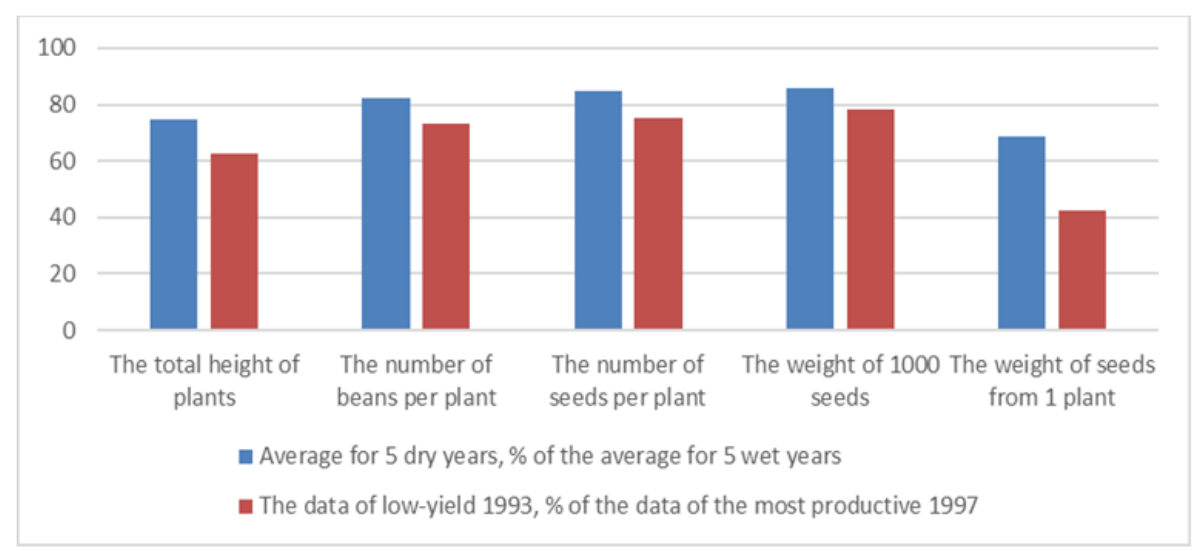

Figure 3. The influence of arid conditions of the growing season on the reduction of soybean yield structure.

The data of the low-yielding drought year 2013 in comparison with the most productive sufficiently provided with moisture year 2017, clearly shows the negative effect of lack of moisture: the height of plants was - $62,4 \%$, the number of beans per plant - 73.4; the number of seeds per plant - 75.2; weight of 1000 seeds - 78.2; seed weight per plant $-42.4 \%$.

In the arid conditions, abortiveness of flowers, buds and young beans is noted, which is associated not only with lighting conditions and excessive thickening of crops. In very contrast of the moisturizing years (2013 and 2017) we carried out a record of the loss of buds, flowers and beans. This work was carried out on 10 model plants with four repetitions. The results of the calculation showed that in a favorable year with moisture supply, the plants formed much more buds, their losses were smaller, which dramatically increased the average number of beans during ripening (Figure 4). Comparing the estimated number of beans were left during the ripening of plants, it was found that soybeans lose not only flowers but also young beans. On the average, 18.1 beans were formed on one plant during the dry growing season, but with favorable moisture, this indicator was - 29.0 beans, which was higher by $60.2 \%$ compared to previous figures. Losses from the fall of generative organs during the growing season were significant: in dry years - 81.9, favorable for moisture $-78.0 \%$.

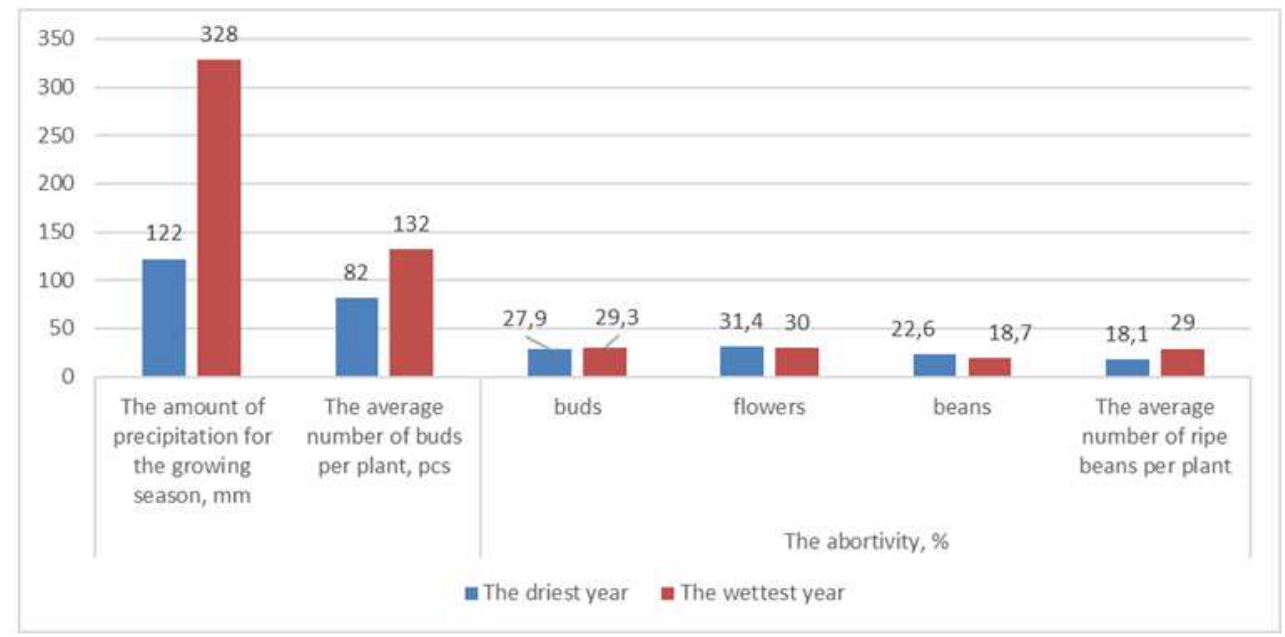

Figure 4. Abortivity of buds, flowers and soybeans depending on the conditions of the growing season.

The decrease in total seed weight was observed in dry years and it was the second most important factor after the decrease in the number of three-seeded beans. It should be noted that in these years the plants, more actively used for the formation of seeds spare substances of the stem and the decay products of structural compounds of dead vegetative 
organs. There is no connection between the dry year and the mobilization of secondary sources, because the latter was the maximum in the years of intensive abortion of flowers. In the dry years, the picture also varied greatly depending on the nature of the weather during different growing seasons.

Counting beans with different amounts of seeds was performed on 25 plants with four repetitions. The number of beans with three seeds under conditions of sufficient moisture increased significantly (Table 3 ). It helped to increase the total number of them per plant. In the arid conditions of the growing season the number of one-seed beans was very high $-31 \%$ (with favorable moisture - 17\%), two-seed beans - 56\% (in the year of favorable moisture $63 \%$ ). The total number of three-seed beans in the conditions of sufficient moisture was greater $-20 \%$, in arid conditions $13 \%$. The average number of beans per plant in arid conditions was 18.1 , in the conditions of favorable moisture 29.0 .

Table 3. The ratio (\%) of one-, two- and three-seed beans depending on the moisture conditions.

\begin{tabular}{|c|c|c|c|c|}
\hline \multirow{2}{*}{ Years } & \multicolumn{3}{|c|}{ Number of beans with seeds } & \multirow{2}{*}{ Seed yield, $t$ / ha } \\
\hline & One-seed & Two-seed & Three-seed & \\
\hline arid & 31 & 56 & 13 & 0,87 \\
\hline wet & 17 & 63 & 20 & 2,01 \\
\hline $\mathrm{SSD}_{0,5}$ & 1,8 & 2,1 & 0,7 & 0,6 \\
\hline
\end{tabular}

Drought conditions cause a sharp decrease in the number of three-seed beans and an increase in one-seed beans, which was the main reason for the decrease in the total seed yield. There was an abortion of flowers, buds and young beans, which is associated with poor nutrition and moisture.

\section{Conclusions}

Studying the nature of growth and the development of soy plants established a close relationship with the moisture content in the soil for the sowing period. Lack of moisture during the growing season of soy affected its overall productivity due to the growth and the development, reducing the size of the leaf surface, the number and size of branches, accelerating the aging and death of vegetative organs.

The indicators of photosynthetic activity of soybean crops were much higher in years with better moisture supply. Fluctuations in the rate of net productivity of photosynthesis by years ranged from 5.3 (the driest year) to $7.0 \mathrm{~g} / \mathrm{m}^{2}$ day (favorable for moisture year). The average indicator of net productivity of photosynthesis for years of favorable moisture was $6.5 \mathrm{~g} / \mathrm{m}^{2}$ day, in dry years it decreased by $10.8 \%$. The photosynthetic potential of soybean crops on the average for 5 dry years was at the level of 2.5 million $\mathrm{m}^{2}$ / day during the branching-flowering period, then it was reduced by $16 \%$, which was a direct effect of lack of moisture in the soil. During the years of favorable soil moisture, the photosynthetic potential was quite high and remained for a longer period within 2.7 million $\mathrm{m}^{2} /$ day.

The total height of plants on average for 5 dry years was lower and was $74.5 \%$ of the average 5 sufficiently moistureprovided years. On the average, 18.1 beans were formed on one plant during the dry growing season, but with favorable moisture, this indicator was -29.0 beans, which was higher by $60.2 \%$ compared to previous figures. Losses from the fall of generative organs during the growing season were significant: in dry years -81.9 , favorable for moisture $-78.0 \%$.

In the conditions of sufficient moisture, the number of beans with three seeds has increased. Arid conditions of the growing season cause a sharp decrease in the number of three seed beans (by 7\%) and an increase in one-seed beans (by
$14 \%$ ), which was the main reason for the decrease in total seed yield.

\section{Recommendations}

According to the results of field and laboratory studies, as well as their economic and bioenergy analysis, it was found that soybean cultivation should take place in conditions of sufficient moisture.

In the territory of the Left-Bank Forest-Steppe of Ukraine, in order to increase the yield and quality of soybean grain, it is recommended to grow early-ripening varieties of soybean; sowing of soybeans should be carried out during the first decade of May; early-ripening varieties of soybeans sow in the usual row method; it is possible to reduce the seeding rate of soybean for $10-15 \%$ by increasing the between rows to 45 $\mathrm{cm}$ without reducing it's productivity.

\section{References}

[1] Arango M. R., Craviotto R. M. and others (2006) Description of the environmental damage on soybean seeds. Seed Science and Technology, 34, 133-141.

[2] Rozhkov A. O., Karpuk L. M., Mikheeva O. O. et al (2020) The yield of soybean varieties depending on the combination of different sowing methods and seeding rates in the Eastern Forest-Steppe of Ukraine. EuroAsian Journal of BioSciences, 14 (1), 2049-2060.

[3] Grigorchuk N. F., Jakubenko O. V. (2013) Creation of varieties of early ripening soy. Science-technical bulletin Institute of oilseeds NAAN, 19, 43-48.

[4] Shevnikov M. (2019) Scientific basis of the development of the basic elements in the technology of soybean sowing in the conditions of forest-steppe of Ukraine. - Current state, challenges and prospects for research in natural sciences: Collective monograph. - Liha-Press, 192-216.

[5] Lotysh I. (2017) The formation of the leaf surface area of soybean crops depending on the sort, method of sowing and sowing rate in conditions of insufficient moisture of the Forest-Steppe. Bulletin of the Poltava State Agrarian Academy. № 1-2, 167-171. 
[6] Shevnikov, M. Ya., Milenko, O. H., \& Lotysh, I. I. (2018). The productivity of soy sorts depending on elements of growing technology. Bulletin of Poltava State Agrarian Academy, (3), 15-21. doi: 10.31210/visnyk2018.03.02.

[7] Petrychenko V. F., Drobitko O. M. (2009) The improvement of the model of soybean growing technology for seeds in the conditions of the south-western steppe of Ukraine. Feed and feed production, 64, 3-9.

[8] Briguglio M. (2014) Variability in kunitz trypsin inhibitor contents and activity in Argentinian soybean cultivars. Developing Global Soy Blueprint for a Safe Secure and Sustainable Supply: VIII World Soybean conference research, August 10-15, Beijng, China.

[9] Ogurtsov E. M. (2016) Adaptive technology of soybean cultivation in the Eastern Forest-Steppe of Ukraine monograph, Kharkiv, p. 272.

[10] Shevnikov M. Ya. (2018). World agrotechnology textbook/ M. Ya. Shevnikov // 2nd edition, revised and supplemented. Poltava, p. 238.
[11] Kaminsky V. (2006) Agrometeorological bases of production of leguminous crops in Ukraine / V. Kamensky /Bulletin of agrarian science, № 7, 20-25.

[12] Nagorny V. I. (2007). The influence of agroclimatic conditions on the potential of early-ripening and earlyripening soybean varieties / V. I. Nagorny, Yu. O. Romanko // Bulletin of Sumy National Agrarian University. Series ।"Agronomy and Biology〉", № $10-11,57-61$.

[13] Tkalich I. D. (2007). The influence of sowing methods and sowing norms on growth, development and yield of soybeans / I. D. Tkalich // Bull. Institute of Grain Management, № 30, 60 -63 .

[14] Babych A. A. (1996). World land, food and fodder resources / Anatoliy Oleksandrovych Babych/ Agrarian science, p. 200.

[15] Kaminsky V. F. (2006). Complex influence of intensification factors on soybean crop formation in northern Forest-steppe / V. F. Kaminsky // Bulletin of Agrarian Science, № 9, 36-42. 